\title{
IEO model: A novel concept describing the complete metastatic process in the liver microenvironment (Review)
}

\author{
LU WANG $^{1}$, YINAN SUN ${ }^{2}$, MINXIAO YI $^{1}$, WEIHENG ZHAO $^{1}$ and XIANGLIN YUAN ${ }^{1}$ \\ ${ }^{1}$ Department of Oncology; ${ }^{2}$ Division of Cardiology, Department of Internal Medicine, Tongji Hospital, \\ Tongji Medical College, Huazhong University of Science and Technology, Wuhan, Hubei 430030, P.R. China
}

Received July 17, 2019; Accepted January 16, 2020

DOI: $10.3892 / \mathrm{ol} .2020 .11525$

\begin{abstract}
Metastasis is a characteristic behavior of malignant tumor cells. It is determined by the mutual interaction between primary tumor cells and the state of the microenvironment at sites of metastasis, particularly the liver, bone, lungs and brain. In the present review, a novel pattern is defined and termed the IEO model (prI-, prE- and pOst-metastatic niche), for the hepatic metastatic microenvironment which characterizes the complete metastatic process. In the IEO model, the components of the hepatic metastatic niche, including the extracellular matrix, hepatocytes, mesenchymal cells, Kupffer cells, hepatic sinusoidal endothelial cells, hepatic stellate cells and immunocytes are continually remodelled by tumor cells to form various microenvironments during different stages of hepatic metastasis. The IEO model explains the plasticity of the hepatic microenvironment and provides novel insights into the role of different stages of the metastatic niche. This novel concept may provide a basis for advances in theoretical cancer research and for improvements in the complete course management of malignant tumors.
\end{abstract}

\section{Contents}

1. Introduction

2. Pri-metastatic niche

3. Pre-metastatic niche

4. Post-metastatic niche

5. Conclusion

Correspondence to: Professor Xianglin Yuan, Department of Oncology, Tongji Hospital, Tongji Medical College, Huazhong University of Science and Technology, 1095 Jie Fang Road, Wuhan, Hubei 430030, P.R. China

E-mail: yuanxianglin@hust.edu.cn

Key words: IEO model, liver microenvironment, metastasis, tumor progression, extracellular matrix

\section{Introduction}

Due to their specific anatomical structures and biological properties, the majority of the different types of digestive cancer first metastasise to the liver $(1,2)$. The timing of, and the molecular determinants underlying the process of metastasis are largely unknown, and improving the ability to determine these factors has clinical significance (3). A number of studies (4-6) have reported that the metastatic microenvironment is altered before malignant cells metastasise to the liver or lung, forming the pre-metastatic niche. Furthermore, multiple clinical studies (7-10) have revealed that patients with cirrhosis or hepatitis exhibit a lower incidence of hepatic metastasis despite presenting with the same types of primary cancer. This indicates that the liver microenvironment may be modulated by primary liver disease influencing hepatic metastasis, and this altered microenvironment is defined as the pri-metastatic niche. After tumor cells migrate to the liver, parenchymal, immune and mesenchymal cells interact with the tumor cells to modify the cell state and local microenvironment (including cancer-associated fibroblasts and macrophages) to perform specific cancer-associated functions that promote tumor cells colonization, proliferation and evade immune defence, this is termed the post-metastatic niche (11-13). These three different niches are the major components of the IEO model (the pri-, pre- and post-metastatic niche), as described in Table I, explaining the hepatic metastatic niche throughout the complete process of tumor progression.

Hepatic metastasis is the primary form of metastasis in colorectal cancer (CRC) and is the leading cause of CRC-associated mortality worldwide $(3,9)$. Colorectal liver metastasis (CRLM) occurs in $>25 \%$ of patients diagnosed with primary CRC and $50 \%$ of patients during the whole course of the disease (2-5). Thus, it is important to understand the underlying mechanisms behind hepatic metastasis, and to develop measures to prevent or delay this process. According to the seed and soil theory, the process of metastasis can be stratified into two major phases (4). The first phase involves the migration of tumor cells from the primary tumor site to a targeted metastatic tissue, and the second phase involves cell proliferation at the site of metastasis (4). This theory emphasises the importance of the 'soil' or microenvironment during the process of metastasis (12). The liver microenvironment is comprised of numerous components, including hepatocytes, Kupffer cells 
(KCs), hepatic sinusoidal endothelial cells (HSECs), hepatic stellate cells (HSCs), pit cells and the extracellular matrix (ECM) (11). The tumor-associated hepatic niche is regulated via two mechanisms; the tumor-associated microenvironment formed by the primary tumor lesions and the intrinsic microenvironment formed by liver disease $(7,14,15)$. Specific stages include the recruitment of fibroblasts, migration of immune cells, matrix remodelling and the development of vascular networks (11). The metastatic cells pass through the portal vein system into the hepatic sinusoid, and the anchoring of the circulating tumor cells (CTCs) to the hepatic sinus, and its attached cells (HSECs, HSCs and KCs), affects invasion and proliferation $(1,4)$. Additionally, blood flow in the hepatic sinusoids is regulated by the vasoconstrictive properties of HSCs that control the oxygen and nutrient supply $(5,16)$. Fig. 1 provides an overview of the processes underlying pathological metastasis that form the basis of the IEO model, as described in detail in the following sections.

\section{Pri-metastatic niche}

The target organ, with its inherent microenvironment influenced by chronic or acute local disease states, may further affect the occurrence of cancer metastasis from primary tumors (5,7-9). The local microenvironment at the metastatic site forms the pri-metastatic niche. Various diseases affecting the liver (such as fatty liver, cirrhosis, liver steatosis, hepatitis $\mathrm{B}$ and $\mathrm{C}$ infection or acute liver injury) may affect the liver microenvironment and the incidence of hepatic metastasis $(14,15,17)$. Accordingly, the pri-metastatic niche serves an important role in the process of hepatic metastasis.

A study of 5,092 autopsies of colorectal, breast or lung tumors indicated that the incidence of liver metastasis is $28.6 \%$ compared with non-cirrhosis cases, which is higher than the $4.5 \%$ observed in patients with cirrhosis (8). Liver metastasis from CRC is also infrequent in patients with cirrhosis (10\%) compared with non-cirrhosis cases (25\%), indicating that liver cirrhosis substantially reduces the rate of CRLM, perhaps due to the differential properties of the liver microenvironment (10). Moreover, a meta-analysis of data concerning 10,349 patients with CRC from 10 studies was performed to investigate the association between CRLM and local liver disease. Based on this meta-analysis, chronically diseased livers (fatty liver, cirrhosis or chronic hepatitis $\mathrm{B}$ and $\mathrm{C}$ virus infection) exhibited a pri-metastatic niche and a significantly lower incidence of CRLM (14). The mechanism may involve the remodelling of the inherent liver microenvironment components, including fibrosis and the hepatic sinus. Activated immune cells residing in the liver microenvironment of the diseased liver kill metastatic tumor cells that circulate in the bloodstream. During cirrhosis, KCs release pro-inflammatory cytokines to remodel the hepatic immune niche, such as tumor necrosis factor (TNF)- $\alpha$ and interleukin (IL)-1 (14). In an analysis of rats with cirrhosis, Song et al (15) revealed that KCs and CRC cells exhibited upregulated Fas/FasL protein expression, which induced cell apoptosis, and the apoptotic cancer cells are further targeted by infiltrating lymphocytes. Thus, while the activation of KCs in cirrhosis participates in tissue damage and fibrogenesis, it also exerts a protective effect by inhibiting the hepatic metastasis of colon cancer. Seitz (16) reported that liver cirrhosis is associated with high metalloproteinase inhibitor levels and decreased levels of lectins or lectin-binding sites. Patients with liver cirrhosis reduced blood flow from the portal vein that may decreases tumor cell migration to the liver, which may contribute to rare occurrences of liver metastasis. However, cytokine analysis of metastasis of pancreatic cancer to the liver has indicated that in the early phase of metastasis, pancreatic ductal cancer cells decrease IL-6/signal transducer and activator of transcription 3 signalling via a negative feedback loop to construct the microenvironment of liver fibrosis and attract bone marrow-derived cells, promoting pancreatic duct engraftment to the liver (18).

Patients with CRC infected with hepatitis B virus (HBV) or hepatitis $\mathrm{C}$ virus exhibit a lower incidence of metastasis $(8.1 \%)$ and longer survival time compared with that in patients without infection (21.2\%), although they may have a higher probability of developing liver cancer (19). HBV may affect liver-associated immunity and increase cytotoxic liver activity on metastatic cells mediated by T cells, KCs or TNF- $\alpha$ synthesized by liver cells $(8,20,21)$. Metalloproteinase inhibitors, such as metalloproteinase tissue inhibitor-1, have also been isolated from myofibroblasts of diseased livers (cirrhosis and hepatitis) but less so from healthy livers. Disease livers with more TIMP1 may inhibit MMPs expression from tumor cells, and this may explain the lower incidence of metastasis observed in diseased livers $(22,23)$. Furthermore, HBV activates cytotoxic T-cells and $\mathrm{KCs}$, which have the potential to kill metastatic tumor cells when they pass the liver sinuses (24-26). Additionally, HBV may stimulate HBV specific T cells to increase the secretion of TNF- $\alpha$ (27).

Non-alcoholic fatty liver disease (NAFLD) and alcoholic liver disease are major health issues associated with tumor cell metastasis to the liver (28). According to previous studies, high alcohol intake is associated with CRLM $(29,30)$. Both KCs and hepatocytes are affected by alcohol, and high expression of lipopolysaccharides and pro-inflammatory cytokines, such as TNF $\alpha$ and IL- $1 \beta$ changes the hepatic niche and CRC metastasis (28). NAFLD has been used to demonstrate the higher metastatic burden in steatotic livers compared with that in normal livers. NAFLD is characterized by fat accumulation, which alters the local hepatic niche by stimulating triglyceride, recruiting inflammatory cells, increasing $\mathrm{TNF} \alpha$ expression and disrupting the normal structure of ECM. These alterations of the liver microenvironment, including tumor-associated inflammatory cells and aberrant ECM structure may promote colonization of tumor cells and cancer progression with poor outcome (28-30). However, Karube et al (31) demonstrated that fat metabolism disorders inhibit tumor cell proliferation and angiogenesis to prevent tumor growth and reduce the likelihood of metastasis.

\section{Pre-metastatic niche}

As indicated in Fig. 2, prior to the establishment of metastatic lesions in the targeted organ, tumor-associated exosomes, CTCs, immune cells and chemokines affect the liver microenvironment, forming the pre-metastatic niche $(4,6,11,32-34)$.

Tumor-derived exosomes are composed of proteins, mRNAs and microRNAs that regulate pre-metastatic niche formation and affect metastasis (35-37). In the metastatic 
Table I. Characteristic stages of the IEO model in the hepatic metastatic environment.

\begin{tabular}{|c|c|c|c|}
\hline Characteristics & Pri-metastatic niche & Pre-metastatic niche & Post-metastatic niche \\
\hline Definition & $\begin{array}{l}\text { Hepatic IME remodeled by the } \\
\text { chronic or acute local diseases. }\end{array}$ & $\begin{array}{l}\text { Hepatic TME altered by } \\
\text { tumor-associated factors } \\
\text { before tumor cells arrived. }\end{array}$ & $\begin{array}{l}\text { Hepatic TME changed by tumor } \\
\text { cells and their associated factors. }\end{array}$ \\
\hline Bio-factors & Cirrhosis, hepatitis and fatty liver. & $\begin{array}{l}\text { Exosomes, chemokines, } \\
\text { immune cells and CTCs. }\end{array}$ & $\begin{array}{l}\text { Tumor cells, exosomes, } \\
\text { chemokines and immunocytes. }\end{array}$ \\
\hline Tumor-associated & No & Yes & Yes \\
\hline Metastasis-associated & Yes & Yes & Yes \\
\hline
\end{tabular}

IME, inherent microenvironment; TME, tumor microenvironment; CTCs, circulating tumor cells; IEO, pri-, pre- and post-metastatic niches.

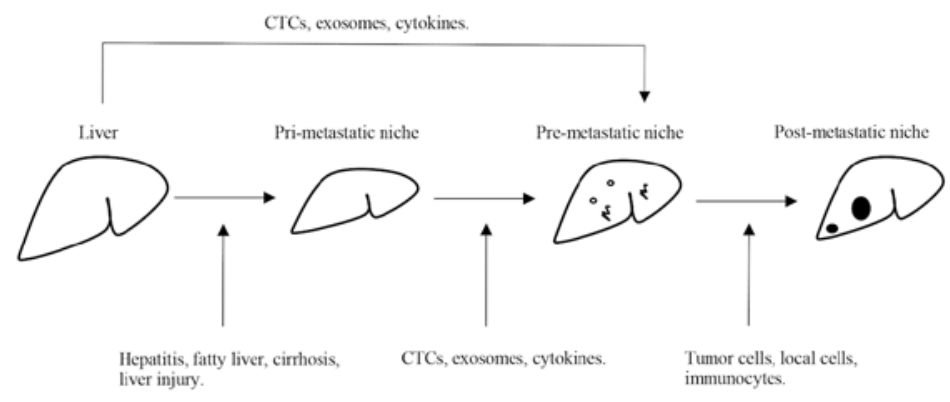

Figure 1. Different liver states in the IEO model. Hepatic disease (hepatitis, fatty liver and cirrhosis) may alter the normal liver microenvironment into the pri-metastatic niche, which is the primary hepatic niche prior to tumor cell migration to the liver. CTCs, immunocytes and their secretions, exosomes and chemokines remodel the hepatic microenvironment prior to pre-metastatic niche and the lesion co-adapts to the microenvironment along with the local hepatic cells to form the post-metastatic niche. CTCs, circulating tumor cells; IEO, prI-, prE- and pOst-metastatic niches.

process, exosomes also affect epithelial-mesenchymal transition, cancer stemness, apoptosis and metastatic angiogenesis via CXCR, integrins or the TGF- $\beta$ signaling pathway (38-40). Wang et al (11) reported that CRC tumor-derived exosomes affect the hepatic niche and increase CXCR4 expression in stromal cells, thus creating a CXCR4-enriched microenvironment suitable for metastasis (11). In addition, pancreatic cancer cells release migration inhibitory factor-associated exosomes that induce TGF- $\beta$ secretion, which results in the production of the glycoprotein fibronectin by HSCs, and the aggregation of bone marrow-derived cells to promote hepatic metastasis (33). Integrins in exosomes influence metastasis to specific organs and prepare the microenvironment for tumor cell arrival, such as integrin $\beta 5$ in liver metastasis and integrin $\alpha 6$ in lung metastasis (41). In addition to tumor-associated exosomes, CTCs are also necessary elements for successful metastasis (18). CTCs circulate to the targeted metastatic organ, evade immune defence via TGF- $\beta$ associated signaling pathways and platelet protection, arrive at the supportive niche and serve as latent tumor seeds in the niche, ultimately proliferating in the host tissue to form the metastatic lesion and altering the liver microenvironment $(42,43)$. CTCs regulate the metastatic microenvironment via cytokine secretion, including TGF- $\beta$ and IL- 1 . The perivascular space around the small blood vessels supports metastasis; it facilitates the proliferation of CTCs and hinders antitumor therapy $(44,45)$. The cytokine signals secreted by the primary tumor may affect the microenvironment of distant organs and form a pre-metastasis niche prior to the arrival of CTCs $(46,47)$. Physical contact between stromal cells and tumor cells, such as the claudin-2-mediated bridge between metastatic cancer cells and hepatocytes, induces c-Met signalling and hepatic metastasis in breast cancer (48). Hepatic sinusoids lined by endothelial cells and basal lamina gaps (49) may support the extravasation of CTCs and result in liver and bone metastasis $(50,51)$. The major factors in anti-metastatic immunity are cytotoxic T and NK cells (52). Furthermore, the liver has a specific immune cell composition, characterised by abundant NK cells, which affects the susceptibility of the target organ to metastasis (4). Compared with levels in the normal mucosa, expression of the inflammatory mediator cyclooxygenase- is upregulated in CRC and to a greater extent in hepatic metastases (53), indicating that inflammation affects disease progression and may serve as a clinical indicator for malignant tumors (54). In HSECs, the vascular cell adhesion protein-1 blockade decreases microvascular formation of the hepatic metastatic lesion $(53,54)$. CTCs, circulating free-DNA, miRNAs and exosomes may potentially be used for the development of critical assays for the early detection of metastasis in patients with CRC and as a therapeutic target.

\section{Post-metastatic niche}

After tumor cells metastasize to the liver, they interact with the liver niche and adapt to their new microenvironment, which is called the post-metastatic niche (Fig. 2). In the new and 


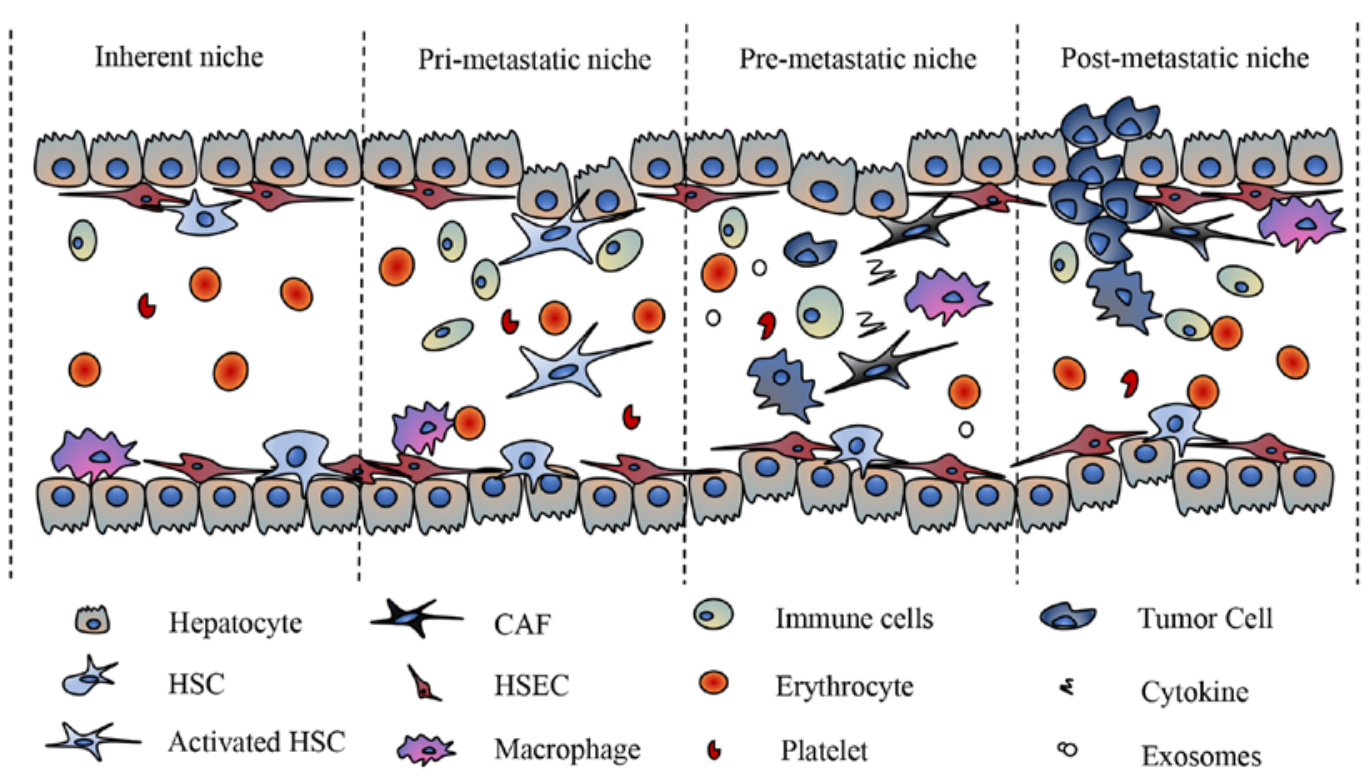

Figure 2. IEO model of the metastatic process in liver microenvironment. Microcirculation in hepatic sinusoid and hepatic local cells may be remoulded by the primary liver disease and the tumor-associated HSCs, macrophage and exosomes. CAF, cancer-associated fibroblasts; HSEC, hepatic sinusoidal endothelial cells; HSCs, hepatic stellate cells; IEO, prI-, prE- and pOst-metastatic niches.

challenging metastatic niche, newly established tumor cells must acquire the ability to survive immune cell attacks (55-58).

The interaction between the hepatic innate immune response and tumor cells is a double-edged sword for tumor metastasis $(55,56)$. Although an initially effective defence can inhibit CTCs via the cytotoxic attack of KCs and NK cells (57), immune cells also promote tumor invasiveness and metastasis via various mechanisms, such as the activation of angiogenesis (55) and a pro-tumorigenic phenotype to promote tumor cell proliferation $(56,58)$. Neutrophils or tumor-associated neutrophils exhibit high levels of plasticity in order to regulate the tumor microenvironment (59). They are also associated with the formation of the pancreatic liver metastatic microenvironment (60). The neutrophil subtype that infiltrates at the early phase of metastasis recruits macrophages and fibroblasts, and promotes the formation of metastatic lesions (61). Neutrophils promote tumor invasion (59), and tumor-associated neutrophils express immunosuppressive factors, such as TGF- $\beta$ and FGF2 (62). CXCR2 protein expression in neutrophils during liver metastasis serves an important role in the early phase of tumor development and accelerates fibroblast anchoring to tumor cells in the hepatic sinus (60). Tumor-associated neutrophils may promote fibroblast growth factor 2 (FGF2), which is primarily expressed in and released from the ECM (12). The normalisation of microvessels in the tumor microenvironment is associated with FGF2 (63), which promotes vascular formation in liver metastases and induces an immune response in endothelial cells to recruit more immune cells (64). Tumor-infiltrating lymphocytes (TILs), an indicator of the anticancer immune response, influence cancer progression, metastasis and chemoresistance and are superior in the TNM classification as a predictor of survival in patients with digestive and lung cancer (65). A high number of TILs in the metastatic tumor is associated with improved clinical outcomes, overall response rates and chemotherapeutic outcomes (65). Moreover, patients with CRC exhibit reduced sensitivity to programmed cell death protein 1 (PD-1) and programmed cell death 1 ligand 1 (PD-L1), with the exception of patients with mismatch repair (MMR) genes deficiencies, such as MSH2, MSH6, MLH1 or PMS2 gene (66). The unique immune microenvironment in the liver forms a special immune tolerance type. The mechanism underlying immune tolerance involves the induction of surface immune suppression ligands of T cells and suppression of the immune receptor expression in liver cells and HSCs (65-67). The post-metastasis microenvironment may enhance immune cell infiltration and increase immunosuppression checkpoints so that sensitivity to PD-1/PD-L1 is greater in MMR-deficient CRC compared with that in MMR-proficient CRC (67). Additionally, decreased TGF- $\beta$ protein expression levels in the post-metastatic niche may increase the activation of cytotoxic $\mathrm{T}$ cell-dependent processes and change MMR-proficient CRC cells to immune-hot cells (68). During metastasis, $\alpha$-SMA-positive stromal cells present on the interstitial surface of the tumor, and the residual fibroblasts differentiate into myofibroblasts that express collagen in the periphery (69,70). According to microenvironmental change, three distinct growth patterns have been described in CRC adenocarcinoma liver metastases (69).

In the replacement growth pattern, the liver structure is preserved. In the pushing growth pattern, the hepatic lobules extend to one side and the liver stromal cells surround the metastatic lesion, and in the desmoplastic growth pattern, a fibrous ring separates the hepatic stromal tissue from the metastatic lesion (70). The survival and proliferation of cancer cells at the metastatic site is important for the establishment of metastatic tumors and the re-expression of E-cadherin on cancer cells at the metastatic site promotes proliferation in breast cancer (71). Further, if the hepatic sinus blood vessel is blocked by a large number of tumor cells and blood flow is obstructed, the inflammatory response of ischemia-reperfusion is initiated $(72,73)$. 
This may result in the release of nitric oxide (NO) and reactive oxygen species in local HSECs and KCs $(72,73)$. The release of NO and interferon $\gamma$ by HSECs entering the hepatic sinus results in the upregulation of FasL, initiating apoptosis in $95 \%$ of metastatic tumor cells (74).

\section{Conclusion}

The liver is the most common site of metastasis for various types gastrointestinal cancers from the portal vein system (2-4,41-43). A deeper understanding of the process of metastasis and cancer recurrence may be beneficial for the identification of novel treatment strategies. A novel concept for the metastatic environment referred to as the IEO model (pri-, pre- and post-metastatic niche) to explain the key steps in metastasis has been described in the present review. The liver microenvironment is formed by invading tumor cells and the immune system. Local cells in the liver and tumor cells develop complex interaction networks and adaptions, which may either inhibit or promote tumor metastasis.

The IEO model provides novel insights into the prevention of tumor metastasis by identifying interventions targeting the liver microenvironment mediated by liver diseases. The model may be used to establish a comprehensive disease management system for the prevention and treatment of liver metastasis, from a microenvironmental perspective.

\section{Acknowledgements}

Not applicable.

\section{Funding}

The present study was funded by the National Natural Science Foundation of China (grant no. 81773360).

\section{Availability of data and materials}

Not applicable.

\section{Authors' contributions}

LW contributed to the conception of the study, writing the manuscript and performing the literature search. YS, MY and $\mathrm{WZ}$ conducted analysis and revised the manuscript. XY performed analysis and the quality assessment of the study. All authors read and approved the final manuscript.

\section{Ethics approval and consent to participate}

Not applicable.

\section{Patient consent for publication}

Not applicable.

\section{Competing interests}

The authors declare that they have no competing interests.

\section{References}

1. Denève E, Riethdorf S, Ramos J, Nocca D, Coffy A, Daurès JP, Maudelonde T, Fabre JM, Pantel K and Alix-Panabières C: Capture of viable circulating tumor cells in the liver of colorectal cancer patients. Clin Chem 59: 1384-1392, 2013.

2. Obenauf AC and Massaguè J: Surviving at a distance: Organ specific metastasis. Trends Cancer 1: 76-91, 2015.

3. Hu Z, Ding J, Ma Z, Sun R, Seoane JA, Scott Shaffer J, Suarez CJ, Berghoff AS, Cremolini C, Falcone A, et al: Quantitative evidence for early metastatic seeding in colorectal cancer. Nat Genet 51: 1113-1122, 2019.

4. Massaguè $J$ and Obenauf AC: Metastatic colonization by circulating tumor cells. Nature 529: 298-306, 2016.

5. Van den Eynden GG, Majeed AW, Illemann M, Vermeulen PB, Bird NC, Høyer-Hansen G, Eefsen RL, Reynolds AR and Brodt P: The multifaceted role of the microenvironment in liver metastasis: Biology and clinical implications. Cancer Res 73: 2031-2043, 2013.

6. Guo Y, Ji X, Liu J, Fan D, Zhou Q, Chen C, Wang W, Wang G, Wang $\mathrm{H}$, Yuan W, et al: Effects of exosomes on pre-metastatic niche formation in tumors. Mol Cancer 18: 39, 2019.

7. Li Destri G, Castaing M, Ferlito F, Minutolo V, Di Cataldo A and Puleo S: Rare hepatic metastases of colorectal cancer in livers with symptomatic HBV and HCV hepatitis. Ann Ital Chir 84: 323-327, 2013.

8. Qiu HB, Zhang LY, Zeng ZL, Wang ZQ, Luo HY, Keshari RP, Zhou ZW and Xu RH: HBV infection decreases risk of liver metastasis in patients with colorectal cancer: A cohort study. World J Gastroenterol 17: 804-808, 2011.

9. Kondo T, Okabayashi K, Hasegawa H, Tsuruta M, Shigeta K and Kitagawa Y: The impact of hepatic fibrosis on the incidence of liver metastasis from colorectal cancer. Br J Cancer 115: 34-39, 2016.

10. Chiou WY, Chang CM, Tseng KC, Hung SK, Lin HY, Chen YC, Su YC, Tseng CW, Tsai SJ, Lee MS and Li CY: Effect of liver cirrhosis on metastasis in colorectal cancer patients: A nationwide population-based cohort study. Jpn J Clin Oncol 45: 160-168, 2015.

11. Wang X, Ding X, Nan L, Wang Y, Wang J, Yan Z, Zhang W, Sun J, Zhu W, Ni B, et al: Investigation of the roles of exosomes in colorectal cancer liver metastasis. Oncol Rep 33: 2445-2453, 2015.

12. Gordon-Weeks AN, Lim SY, Yuzhalin AE, Jones K, Markelc B, Kim KJ, Buzzelli JN, Fokas E, Cao Y, Smart S and Muschel R: Neutrophils promote hepatic metastasis growth through fibroblast growth factor 2-dependent angiogenesis in mice. Hepatology 65: 1920-1935, 2017.

13. Mendonsa AM, VanSaun MN, Ustione A, Piston DW, Fingleton BM and Gorden DL: Host and tumor derived MMP13 regulate extravasation and establishment of colorectal metastases in the liver. Mol Cancer 14: 49, 2015

14. Cai B, Liao K, Song XQ, Wei WY, Zhuang Y and Zhang S: Patients with chronically diseased livers have lower incidence of colorectal liver metastases: A meta-analysis. PLoS One 9: e108618, 2014.

15. Song E, Chen J, Ouyang N, Wang M, Exton MS and Heemann U: Kupffer cells of cirrhotic rat livers sensitize colon cancer cells to Fas mediated apoptosis. Br J Cancer 84: 1265-1271, 2001.

16. Seitz G: Why are metastases in cirrhotic livers so rare? Ultraschall Med 10: 123-126, 1989 (In German).

17. Seymour K and Charnley RM: Evidence that metastasis is less common in cirrhotic than normal liver: A systematic review of post-mortem case-control studies. Br J Surg 86: 1237-1242, 1999.

18. Lee JW, Stone ML, Porrett PM, Thomas SK, Komar CA, Li JH, Delman D, Graham K, Gladney WL, Hua X, et al: Hepatocytes direct the formation of a pro-metastatic niche in the liver. Nature 567: 249-252, 2019.

19. Utsunomiya T, Saitsu H, Saku M, Yoshida K, Matsumata T, Shimada M and Sugimachi K: Rare occurrence of colorectal cancer metastasis in livers infected with hepatitis B or C virus. Am J Surg 177: 279-281, 1999.

20. Qian HG, Zhang J, Leng JH, Zhou GQ, Wu JH, Tian XY, Yang Y and Hao CY: Association of hepatitis $\mathrm{B}$ virus infection and cirrhosis with liver metastasis in colorectal cancer. Zhonghua Wei Chang Wai Ke Za Zhi 13: 202-204, 2010 (In Chinese).

21. Song E, Chen J, Ou Q and Su F: Rare occurrence of metastatic colorectal cancers in livers with replicative hepatitis B infection. Am J Surg 181: 529-533, 2001. 
22. Zeng ZS, Sun Y, Shu WP and Guillem JG: Tissue inhibitor of metalloproteinase-3 is a basement membrane-associated protein that is significantly decreased in human colorectal cancer. Dis Colon Rectum 44: 1290-1296, 2001.

23. Cheng L, Geng L, Dai B, Zheng T, Fu J, Qiao L, Cai W, Wang Y and Yang J: Repression of let-7a cluster prevents adhesion of colorectal cancer cells by enforcing a mesenchymal phenotype in presence of liver inflammation. Cell Death Dis 9: 489, 2018.

24. Uetsuji S, Yamamura M, Yamamichi K, Okuda Y, Takada H and Hioki K: Absence of colorectal cancer metastasis to the cirrhotic liver. Am J Surg 164: 176-177, 1992.

25. Wu JF and Chang MH: Natural history of chronic hepatitis B virus infection from infancy to adult life-the mechanism of inflammation triggering and long-term impacts. J Biomed Sci 22: $92,2015$.

26. Tordjmann T, Soulie A, Guettier C, Schmidt M, Berthou C, Beaugrand $\mathrm{M}$ and Sasportes $\mathrm{M}$ : Perforin and granzyme B lytic protein expression during chronic viral and autoimmune hepatitis. Liver 18: 391-397, 1998.

27. Lara-PezziE,MajanoPL,Gómez-Gonzalo M,García-MonzónC, Moreno-Otero R, Levrero M and López-Cabrera M: The hepatitis B virus $\mathrm{X}$ protein up-regulates tumor necrosis factor alpha gene expression in hepatocytes. Hepatology 28: 1013-1021, 1998.

28. McVicker B, Tuma DJ, Lazure KE, Thomas P and Casey CA: Alcohol, carcinoembryonic antigen processing and colorectal liver metastases. Adv Exp Med Biol 815: 295-311, 2015.

29. Maeda M, Nagawa H, Maeda T, Koike $H$ and Kasai H: Alcohol consumption enhances liver metastasis in colorectal carcinoma patients. Cancer 83: 1483-1488, 1998.

30. Dong H, Tang J, Li LH, Ge J, Chen X, Ding J, Men HT, Luo WX, Du Y, Li C, et al: Serum carbohydrate antigen 19-9 as an indicator of liver metastasis in colorectal carcinoma cases. Asian Pac J Cancer Prev 14: 909-913, 2013.

31. Karube H, Masuda H, Hayashi S, Ishii Y and Nemoto N: Fatty liver suppressed the angiogenesis in liver metastatic lesions Hepatogastroenterology 47: 1541-1545, 2000.

32. Pancione M, Giordano G, Remo A, Febbraro A, Sabatino L, Manfrin E, Ceccarelli $M$ and Colantuoni V: Immune escape mechanisms in colorectal cancer pathogenesis and liver metastasis. J Immunol Res 2014: 686879, 2014.

33. Alderton GK: Metastasis. Exosomes drive premetastatic niche formation. Nat Rev Cancer 12: 447, 2012.

34. Kosaka N, Iguchi H, Hagiwara K, Yoshioka Y, Takeshita F and Ochiya T: Neutral sphingomyelinase 2 (nSMase2)-dependent exosomal transfer of angiogenic microRNAs regulate cancer cell metastasis. J Biol Chem 288: 10849-10859, 2013.

35. Théry C, Ostrowski M and Segura E: Membrane vesicles as conveyors of immune responses. Nat Rev Immunol 9: 581-593, 2009.

36. Valadi H, Ekström K, Bossios A, Sjöstrand M, Lee JJ and Lötvall JO: Exosome-mediated transfer of mRNAs and microRNAs is a novel mechanism of genetic exchange between cells. Nat Cell Biol 9: 654-672, 2007.

37. Bang $\mathrm{C}$ and Thum T: Exosomes: New players in cell-cell communication. Int J Biochem Cell Biol 44: 2060-2064, 2012.

38. Hood JL, Pan H, Lanza GM and Wickline SA; Consortium for Translational Research in Advanced Imaging and Nanomedicine (C-TRAIN): Paracrine induction of endothelium by tumor exosomes. Lab Invest 89: 1317-1328, 2009.

39. Balaj L, Lessard R, Dai L, Cho YJ, Pomeroy SL, Breakefield XO and Skog J: Tumor microvesicles contain retrotransposon elements and amplified oncogene sequences. Nat Commun 2 : 180,2011

40. Aliotta JM, Pereira M, Johnson KW, de Paz N, Dooner MS, Puente N, Ayala C, Brilliant K, Berz D, Lee D, et al: Microvesicle entry into marrow cells mediates tissue-specific changes in mRNA by direct delivery of mRNA and induction of transcription. Exp Hematol 38: 233-245, 2010.

41. Hoshino A, Costa-Silva B, Shen TL, Rodrigues G, Hashimoto A, Tesic Mark M, Molina H, Kohsaka S, Di Giannatale A, Ceder S, et al: Tumor exosome integrins determine organotropic metastasis. Nature 527: 329-335, 2015

42. Labelle M, Begum S and Hynes RO: Direct signaling between platelets and cancer cells induces an epithelial-mesenchymal-like transition and promotes metastasis. Cancer Res 20: 579-560, 2011.

43. Houg DS and Bijlsma MF: The hepatic pre-metastatic niche in pancreatic ductal adenocarcinoma. Mol Cancer 17: 95, 2018.
44. Hambardzumyan D, Becher OJ, Rosenblum MK, Pandolfi PP, Manova-Todorova K and Holland EC: PI3K pathway regulates survival of cancer stem cells residing in the perivascular niche following radiation in medulloblastoma in vivo. Genes Dev 22 436-448, 2008

45. Cao ZW, Ding BS, Guo PP, Lee SB, Butler JM, Casey SC, Simons M, Tam W, Felsher DW, Shido K, et al: Angiocrine factors deployed by tumor vascular niche induce B cell lymphoma invasiveness and chemoresistance. Cancer Res 25: 350-365, 2014.

46. Kaplan RN, Riba RD, Zacharoulis S, Bramley AH, Vincent L, Costa C, MacDonald DD, Jin DK, Shido K, Kerns SA, et al: VEGFR1-positive haematopoietic bone marrow progenitors initiate the pre-metastatic niche. Nature 438: 820-827, 2005.

47. McAllister SS and Weinberg RA: The tumor-induced systemic environment as a critical regulator of cancer progression and metastasis. Nat Cell Biol 16: 717-727, 2014.

48. Tabariés S, Dupuy F, Dong Z, Monast A, Annis MG, Spicer J, Ferri LE, Omeroglu A, Basik M, Amir E, et al: Claudin-2 promotes breast cancer liver metastasis by facilitating tumor cell interactions with hepatocytes. Mol Cell Biol 32: 2979-2991, 2012.

49. Aird WC: Phenotypic heterogeneity of the endothelium: II. Representative vascular beds. Circ Res 100: 174-190, 2007.

50. Nguyen DX, Bos PD and Massagué J: Metastasis: From dissemination to organ-specific colonization. Nat Rev Cancer 9: 274-284, 2009.

51. Budczies J, von Winterfeld M, Klauschen F, Bockmayr M, Lennerz JK, Denkert C, Wolf T, Warth A, Dietel M, Anagnostopoulos I, et al: The landscape of metastatic progression patterns across major human cancers. Oncotarget 6: 570-583, 2015.

52. Eyles J, Puaux AL, Wang X, Toh B, Prakash C, Hong M, Tan TG, Zheng L, Ong LC, Jin Y, et al: Tumor cells disseminate early, but immunosurveillance limits metastatic outgrowth, in a mouse model of melanoma. J Clin Invest 120: 2030-2039, 2010.

53. Chen WS, Wei SJ, Liu JM, Hsiao M, Kou-Lin J and Yang WK: Tumor invasiveness and liver metastasis of colon cancer cells correlated with cyclooxygenase-2 (COX-2) expression and inhibited by a COX-2-selective inhibitor, etodolac. Int J Cancer 91: 894-899, 2001

54. Wang D, Sun H, Wei J, Cen B and DuBois RN: CXCL1 is critical for premetastatic niche formation and metastasis in colorectal cancer. Cancer Res 77: 3655-3665, 2017.

55. Murdoch C, Muthana M, Coffelt SB and Lewis CE: The role of myeloid cells in the promotion of tumor angiogenesis. Nat Rev Cancer 8: 618-631, 2008.

56. Flavell RA, Sanjabi S, Wrzesinski SH and Licona-Limón P: The polarization of immune cells in the tumor environment by TGFbeta. Nat Rev Immunol 10: 554-567, 2010.

57. Luzzi KJ, MacDonald IC, Schmidt EE, Kerkvliet N, Morris VL, Chambers AF and Groom AC: Multistep nature of metastatic inefficiency: Dormancy of solitary cells after successful extravasation and limited survival of early micrometastases. Am J Pathol 153: 865-873, 1998.

58. Brodt P: Role of the microenvironment in liver metastasis: From pre- to prometastatic niches. Clin Cancer Res 22: 5971-5982, 2016.

59. Fridlender ZG, Sun J, Kim S, Kapoor V, Cheng G, Ling L, Worthen GS and Albelda SM: Polarization of tumor-associated neutrophil phenotype by TGF-beta: 'N1' versus 'N2' TAN. Cancer Res 16: 183-194, 2009.

60. Steele CW, Karim SA, Leach JDG, Bailey P, Upstill-Goddard R, Rishi L, Foth M, Bryson S, McDaid K, Wilson Z, et al: CXCR2 inhibition profoundly suppresses metastases and augments immunotherapy in pancreatic ductal adenocarcinoma. Cancer Res 29: 832-845, 2016

61. Hirai H, Fujishita T, Kurimoto K, Miyachi H, Kitano S, Inamoto S, Itatani Y, Saitou M, Maekawa T and Taketo MM: CCR1-mediated accumulation of myeloid cells in the liver microenvironment promoting mouse colon cancer metastasis. Clin Exp Metastasis 31: 977-989, 2014.

62. Elpek KG, Cremasco V, Shen H, Harvey CJ, Wucherpfennig KW, Goldstein DR, Monach PA and Turley SJ: The tumor microenvironment shapes lineage, transcriptional, and functional diversity of infiltrating myeloid cells. Cancer Immunol Res 2: 655-667, 2014.

63. Yuan H, Li ZM, Shao J, Ji WX, Xia W and Lu S: FGF2/FGFR1 regulates autophagy in FGFR1-amplified non-small cell lung cancer cells. J Exp Clin Cancer Res 36: 72, 2017.

64. Presta M, Andrés G, Leali D, Dell'Era P and Ronca R: Inflammatory cells and chemokines sustain FGF2-induced angiogenesis. Eur Cytokine Netw 20: 39-50, 2009. 
65. Shibutani M, Maeda K, Nagahara H, Fukuoka T, Matsutani S, Kashiwagi S, Tanaka H, Hirakawa K and Ohira M: A comparison of the local immune status between the primary and metastatic tumor in colorectal cancer: A retrospective study. BMC Cancer 18: 371, 2018.

66. Le DT, Durham JN, Smith KN, Wang H, Bartlett BR, Aulakh LK, Lu S, Kemberling H, Wilt C, Luber BS, et al: Mismatch repair deficiency predicts response of solid tumors to PD-1 blockade. Science 357: 409-413, 2017.

67. Zhou G, Noordam L, Sprengers D, Doukas M, Boor PPC, van Beek AA, Erkens R, Mancham S, Grünhagen D, Menon AG, et al: Blockade of LAG3 enhances responses of tumor-infiltrating T cells in mismatch repair-proficient liver metastases of colorectal cancer. Oncoimmunology 7: e1448332, 2018.

68. Tauriello DVF, Palomo-Ponce S, Stork D, Berenguer-Llergo A, Badia-Ramentol J, Iglesias M, Sevillano M, Ibiza S, Cañellas A, Hernando-Momblona X, et al: TGF $\beta$ drives immune evasion in genetically reconstituted colon cancer metastasis. Nature 554: 538-543, 2018

69. Vermeulen PB, Colpaert C, Salgado R, Royers R, Hellemans H, Van Den Heuvel E, Goovaerts G, Dirix LY and Van Marck E: Liver metastases from colorectal adenocarcinomas grow in three patterns with different angiogenesis and desmoplasia. J Pathol 195: 336-342, 2001.
70. Bugyik E, Szabó V, Dezső K, Rókusz A, Szücs A, Nagy P, Tóvári J, László V, Döme B and Paku S: Role of (myo)fibroblasts in the development of vascular and connective tissue structure of the $\mathrm{C} 38$ colorectal cancer in mice. Cancer Commun (Lond) 38: 46, 2018.

71. Padmanaban V, Krol I, Suhail Y, Szczerba BM, Aceto N, Bader JS and Ewald AJ: E-cadherin is required for metastasis in multiple models of breast cancer. Nature 573: 439-444, 2019.

72. Wang HH, McIntosh AR, Hasinoff BB, Rector ES, Ahmed N, Nance DM and Orr FW: B16 melanoma cell arrest in the mouse liver induces nitric oxide release and sinusoidal cytotoxicity: A natural hepatic defense against metastasis. Cancer Res 60: 5862-5869, 2000.

73. Yanagida H, Kaibori M, Yoshida H, Habara K, Yamada M, Kamiyama Y and Okumura T: Hepatic ischemia/reperfusion upregulates the susceptibility of hepatocytes to confer the induction of inducible nitric oxide synthase gene expression. Shock 26: 162-168, 2006.

74. Braet F, Nagatsuma K, Saito M, Soon L, Wisse E and Matsuura T: The hepatic sinusoidal endothelial lining and colorectal liver metastases. World J Gastroenterol 13: 821-825, 2007. 